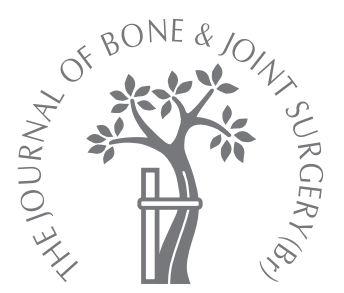

D. Allen, P. E. Beaulé, O. Ramadan, S. Doucette

From the University of Ottawa, Ottawa, Canada

D. Allen, MSc, FRCS Ed(Trauma \& Orth), Consultant Orthopaedic Surgeon Hairmyres Hospital, Eaglesham Road, East Kilbride G75 8RG, UK.

P. E. Beaulé, MD, FRCS C Associate Professor

O. Ramadan, MD, Resident Adult Reconstruction Service - S. Doucette, MSc, Statistician Ottawa Hospital Research Institute

The Ottawa Hospital, General Campus, 501 Smyth Road, Ottawa, Ontario, Canada K1H 8 L6.

Correspondence should be sent to Associate Professor P. E. Beaulé; e-mail: pbeaule@ottawahospital.on.ca

(C)2009 British Editorial Society of Bone and Joint Surgery doi:10.1302/0301-620X.91B5. $22028 \$ 2.00$

$J$ Bone Joint Surg $[\mathrm{Br}]$ 2009;91-B:589-94. Received 7 November 2008; Accepted after revision 21 January 2009

\title{
Prevalence of associated deformities and hip pain in patients with cam-type femoroacetabular impingement
}

Femoroacetabular impingement is a cause of hip pain in adults and is potentially a precursor of osteoarthritis. Our aim in this study was to determine the prevalence of bilateral deformity in patients with symptomatic cam-type femoroacetabular impingement as well as the presence of associated acetabular abnormalities and hip pain. We included all patients aged 55 years or less seen by the senior author for hip pain, with at least one anteroposterior and lateral pelvic radiograph available. All patients with dysplasia and/or arthritis were excluded. A total of 113 patients with a symptomatic cam-impingement deformity of at least one hip was evaluated. There were 82 men and 31 women with a mean age of $\mathbf{3 7 . 9}$ years (16 to 55 )

Bilateral cam-type deformity was present in 88 patients $(77.8 \%)$ while only 23 of those (26.1\%) had bilateral hip pain. Painful hips had a statistically significant higher mean alpha angle than asymptomatic hips $\left(69.9^{\circ}\right.$ vs $\left.63.1^{\circ}, p<0.001\right)$. Hips with an alpha angle of more than $60^{\circ}$ had an odds ratio of being painful of 2.59 (95\% confidence interval 1.32 to 5.08, $p=0.006$ ) compared with those with an alpha angle of less than $60^{\circ}$. Of the 201 hips with a cam-impingement deformity $\mathbf{4 2} \%(84)$ also had a pincer deformity.

Most patients with cam-type femoroacetabular impingement had bilateral deformities and there was an associated acetabular deformity in 84 of 201 patients (42\%). This information is important in order to define the natural history of these deformities, and to determine treatment.

Femoroacetabular impingement (FAI) has recently been described as a cause of pain in the hip in young adults and of osteoarthritis $(\mathrm{OA})$ of the hip ${ }^{1,2}$ with two modes of impingement being described, pincer and cam-type. ${ }^{1,3}$ Pincer-type impingement results from an overprominent acetabular rim abutting against the junction of the femoral head and neck on hip movement. This can occur anterolaterally with a retroverted hip or globally in coxa profunda. ${ }^{3}$ Pincer impingement leads to labral degeneration, ossification and a strip of damage to the articular cartilage located adjacent to the acetabular margin. ${ }^{3}$

Cam-type impingement is caused by a nonspherical portion of the femoral head, usually with a prominence at the anterosuperior headneck junction. ${ }^{4,5}$ On hip movement, as the prominence moves into contact with the congruent acetabulum, the femoral head becomes effectively too large and causes shearing of the articular cartilage. ${ }^{3}$ Cam-impingement can occur secondary to developmental hip problems such as Perthes' disease ${ }^{6}$ or a slipped capital femoral epiphysis (SCFE), ${ }^{7}$ although most patients with FAI have no history of childhood hip problems. It is the predominant pattern, although Beck et $\mathrm{al}^{3}$ have reported a mixed type of deformity in a considerable number of hips.

A number of surgical treatments for FAI have been reported to give good symptomatic relief and improved function. ${ }^{8-12}$ As with other disorders of the hip such as osteonecrosis ${ }^{13}$ and dysplasia,${ }^{14}$ early detection of FAI may be beneficial in optimising both the outcome and the costeffectiveness of surgery when compared with arthroplasty in such patients. ${ }^{15}$ However, like dysplasia, ${ }^{16}$ it is important to determine the severity of the deformity, the risk of progression and the indications for surgery. It is important to understand what makes a deformity symptomatic.

Our aim was to determine the prevalence of bilateral deformity in patients with cam-type FAI as well as the presence of associated acetabular abnormalities and pain.

\section{Patients and Methods}

Our retrospective review was approved by the institutional review board. Between January 2006 and April 2008 patients seen and 


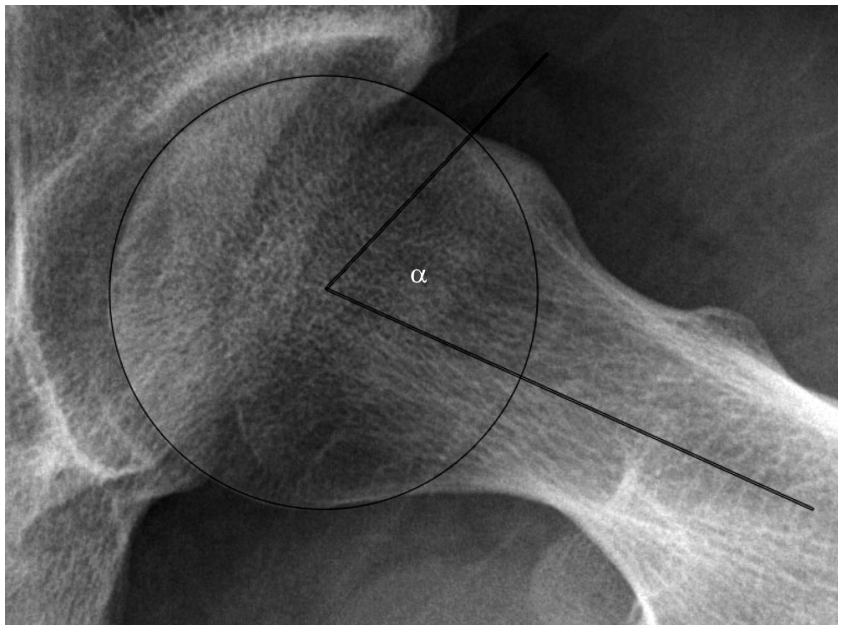

Fig. 1

Lateral radiograph of a hip showing the method of Notzli et al ${ }^{19}$ for assessing the alpha angle.

examined by the senior author (PEB) with pain in the hip, adequate bilateral lateral radiographs of the hips showing at least one hip with a cam-type impingement and a positive impingement sign, were included. The exclusion criteria were skeletal immaturity, age more than 55 years, significant degenerative change (Tönnis grade $>2),{ }^{17}$ the presence of dysplasia (centre-edge angle $<25^{\circ 18}$ and/or Tönnis angle $>10^{\circ}$ ), ${ }^{17}$ other developmental or post-traumatic abnormality or inadequate anteroposterior (AP) pelvic radiographs. Of the 380 patients seen, 267 were excluded because of advanced arthritis in 150, dysplasia in 50, previous childhood disorders in 17 and inappropriate AP pelvic radiographs in 50. This left 113 patients in the study, 82 men and 31 women with a mean age of 37.9 years (16 to 55 ).

Cam-type impingement deformity is defined by measuring the alpha angle ${ }^{19}$ on either the cross-table lateral radiograph with the leg in $15^{\circ}$ of internal rotation or on a Dunn view ${ }^{20}$ with the hip in $90^{\circ}$ of flexion, $20^{\circ}$ of abduction and in neutral rotation. ${ }^{20}$ The alpha angle is measured on the radiograph by placing a circle of best fit over the outline of the femoral head. A line is drawn from the first point on the femoral head-neck junction which is outside the circle to the centre of rotation of the femoral head. A second line is drawn from the centre of the femoral head to the midline of the femoral neck and the angle between these two lines is measured (Fig. 1). Several studies have defined the upper limit of normal for the alpha angle as being $50.5^{\circ} .5,19$ However, since a slightly abnormal alpha angle, e.g. $51^{\circ}$, is within the reported error of measurement, ${ }^{19}$ we applied a cut-off of more than $55.5^{\circ}$ to define the painful camimpingement deformity.

On the AP pelvic radiograph, hips were assessed for signs of pincer-type impingement and the lateral centreedge angle of Wiberg. ${ }^{18}$ Pincer-type impingement was defined as acetabular retroversion, coxa profunda or coxa protrusio. ${ }^{3}$ Acetabular retroversion was recorded as being present if the cross-over $\operatorname{sign}^{21,22}$ and/or ischial $\operatorname{sign}^{23}$ was present on the AP radiograph. A cross-over sign was present when the anterior wall of the acetabulum was seen to cross the posterior wall ${ }^{22}$ and the ischial sign when the ischial spine was prominent. $^{23}$ Coxa profunda was detected on the AP pelvic radiograph if the medial wall of the acetabulum was visible on or medial to the ilioischial line. ${ }^{3}$ Coxa protrusio was documented if the medial edge of the femoral head appeared on or crossed the ilioischial line. ${ }^{3}$ All of these signs are sensitive to the position of the pelvis relative to the plane of the $\mathrm{x}$-ray beam and an assessment of this was undertaken. Rotation was checked by confirming the alignment of the coccyx and symphysis pubis. The tilt of the pelvis was assessed by measuring the height of the sacrococcygeal joint above the symphysis, which is estimated to be $32 \mathrm{~mm}$ in men and $47 \mathrm{~mm}$ in women. ${ }^{24}$

Notes of all the patients were reviewed to determine the presence or absence of pain in the hip on both sides with an associated positive impingement sign. All the radiographs were viewed using the Horizon Picture Archiving and Communications System (PACS) (McKesson Medical Imaging, San Francisco, California) which allows for the manipulation and annotation of radiographs. All the radiographs were assessed by one blinded reviewer (DA). Notzli et al ${ }^{19}$ described the use of measurement of the alpha angle, and when assessing intra- and interobserver variations found the SD to be 3\% and 7\%, respectively.

Statistical analysis. This was performed using Excel (Microsoft, Richmond, Washington) and SPSS version 15.0 software (SPSS Inc., Chicago, Illinois). The twotailed paired $t$-test, the chi-squared test and the intraclass correlation coefficient were used. The odds ratio (OR) was calculated using conditional logistic regression to determine the risk of developing hip pain based on the severity of the bony abnormality.

A p-value $\leq 0.05$ was considered to be significant.

\section{Results}

Prevalence of bilateral cam-type deformity. Of the 113 patients, 88 had bilateral and 25 unilateral cam-type deformity giving a total of 201 hips with cam-type deformity. However, only 23 of the 88 patients had bilateral hip pain. The mean alpha angle was $67.1^{\circ}$ (SD 10.6 , range $39^{\circ}$ to $92^{\circ}$ ). Figure 2 shows the number of symptomatic and asymptomatic hips related to the alpha angle. In 88 patients $(77.8 \%)$ the alpha angle was $>55.5^{\circ}$ in both hips. The mean alpha angle in the hips with cam-impingement was $69.5^{\circ}$ (SD 8.5, range $56^{\circ}$ to $\left.92^{\circ}\right)$. Had the threshold been set at an alpha angle greater than $50.5^{\circ}$, there would have been $96(80 \%)$ patients with a bilateral deformity.

The mean alpha angle in women $\left(62.1^{\circ}\right.$, SD 9.6) was significantly lower than that in men $\left(69.1^{\circ}\right.$, SD 10.4 , $\mathrm{p}<0.001)$. Unilateral impingement was noted in 11 of the 


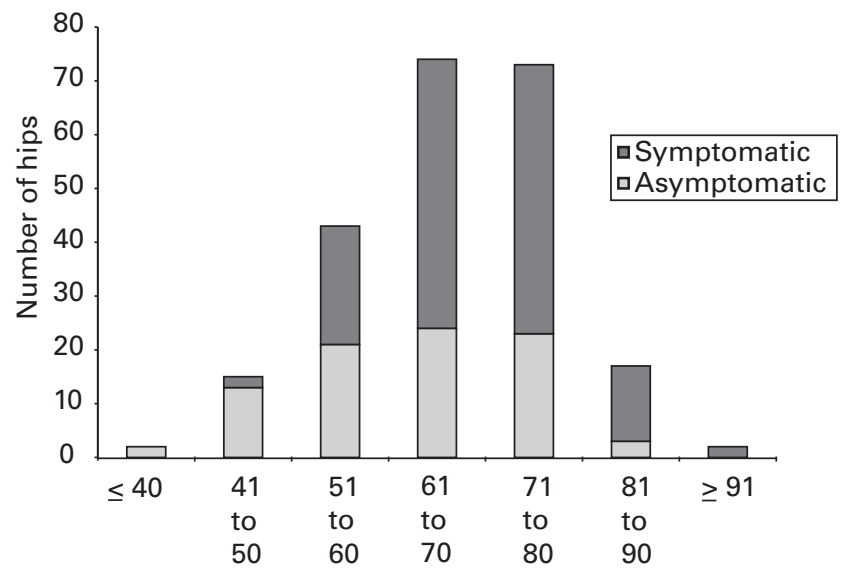

Alpha angle $\left({ }^{\circ}\right)$

Fig. 2

Bar chart of the number of symptomatic and asymptomatic hips in relation to the measured alpha angle.

31 women $(35.5 \%)$ and 14 of the 82 men $(17.1 \%)$. This difference was significant $(\mathrm{p}=0.03)$.

The mean alpha angle for males and females combined for the right hip was $68.0^{\circ}$ (SD 10.2) and for the left hip $66.3^{\circ}$ (SD 11.0). This difference was not statistically significant $(\mathrm{p}=0.21)$. Of the unilateral group, 18 had cam impingement on the right and seven on the left, a ratio of $2.57: 1$. There was a mild, but statistically significant, correlation between the side-to-side alpha angles for individual patients, (intraclass correlation coefficient $=0.32$, $\mathrm{p}<0.001$ ). Patients with unilateral impingement had a significantly lower mean alpha angle on their impingement side $\left(63^{\circ}\right.$, SD 6.7$)$ than in patients with bilateral impingement $\left(70.4^{\circ}, \mathrm{SD} 6.8 ; \mathrm{p}<0.001\right)$.

Associated acetabular abnormalities. Pincer impingement was noted in 98 hips, with 84 of these occurring in hips with a cam-type deformity $(42 \%)$. Acetabular retroversion was present in 53 hips, being bilateral in 21 and unilateral in 11, while coxa profunda was present in 45 hips of which 21 were bilateral. No hips had evidence of coxa protrusio. Of the 201 hips studied, cam-impingement deformity was associated with retroversion in $48(23.9 \%)$ and coxa profunda in $36(17.9 \%)$.

The mean centre-edge angle was $34.8^{\circ}\left(25^{\circ}\right.$ to $\left.56^{\circ}\right)$. Hips with neither coxa profunda nor retroversion had a mean centre-edge angle of $33.6^{\circ}$ (SD 4.6). Those with coxa profunda had a significantly greater mean centre-edge angle $\left(38.7^{\circ}\right.$, SD 6.7 , range $29^{\circ}$ to $\left.56^{\circ}, \mathrm{p}<0.001\right)$, but retroverted hips did not $\left(34.7^{\circ}\right.$, SD 4.4 , range $25^{\circ}$ to $\left.46^{\circ}\right)$.

Association of hip pain with FAI deformity. Only 23 patients with bilateral alpha angles of more than $55.5^{\circ}$ had bilateral symptoms. Four who complained of bilateral hip pain had an alpha angle on one hip of less than $55.5^{\circ}$. These mea-

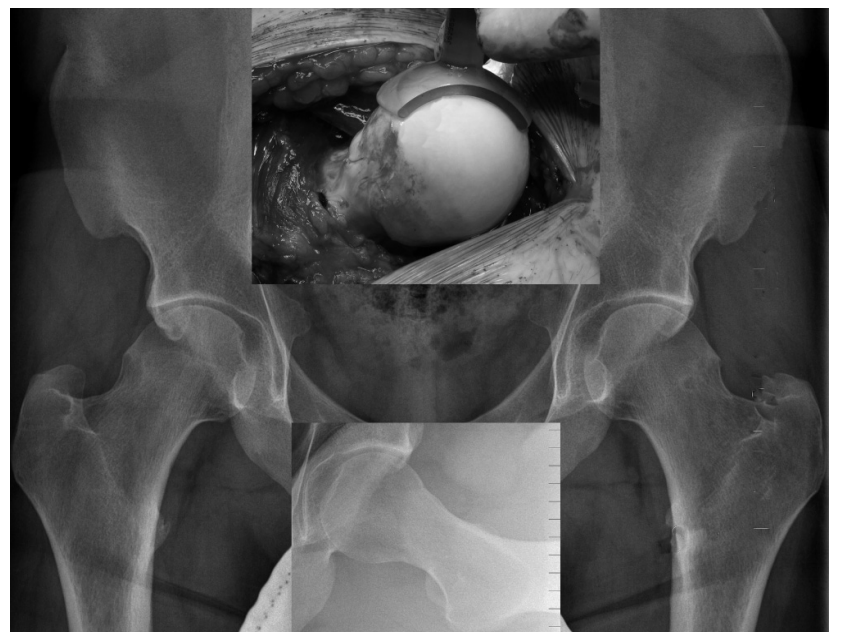

Fig. 3

An anteroposterior pelvic radiograph of a patient with bilateral hip pain showing bilateral prominences and an alpha angle of only $50^{\circ}$ on the left (lower inset lateral radiograph). An intra-operative photograph (upper insert) of the same hip shows a superolateral prominence (seen at the bottom of the head-neck junction on this view).

sured $50^{\circ}, 50^{\circ}, 52^{\circ}$ and $55^{\circ}$, respectively. All four had signs of pincer impingement in these hips (three coxa profunda, one acetabular retroversion). One patient with an alpha angle of $50^{\circ}$ on one side had bilateral pistol-grip deformities ${ }^{25}$ on the AP pelvic radiograph (Fig. 3).

Of the patients who complained of unilateral pain, the mean alpha angle of the painful hips was $69.9^{\circ}$ (SD 8.2), while that of the painless hip was $63.1^{\circ}$ (SD 11.7). This difference was statistically significant $(\mathrm{p}<0.001)$. Comparison of hips with an alpha angle of $61^{\circ}$ to $70^{\circ}$ with those of less or equal to $60^{\circ}$ showed an odds ratio for being painful of $2.59(95 \%$ confidence interval (CI) 1.32 to 5.08, $\mathrm{p}=0.006$ ). Similarly, hips with an alpha angle $>71^{\circ}$ had an odds ratio for being painful of 2.54 (95\% CI 1.3 to 4.96 , $\mathrm{p}=0.007)$.

In patients with bilateral cam-impingement deformity there was no statistically significant difference in age between those who had symptoms unilaterally or bilaterally (37.2 vs 38.2 years, $\mathrm{p}=0.74$ ). There was also no statistically significant difference for gender $(\mathrm{p}=0.20)$. Of the 88 patients with a bilateral alpha angle greater than $55.5^{\circ}$, three of $23(13.0 \%)$ with bilateral pain and 17 of 65 $(26.2 \%)$ with unilateral pain were women $(\mathrm{p}=0.20)$.

Of the 65 patients with bilateral cam-type deformity and unilateral symptoms, there was no significant difference in the prevalence of pincer-type deformity between the symptomatic and asymptomatic hips with an odds ratio of 1.28 (95\% CI 0.83 to $1.96, \mathrm{p}=0.26$ ).

\section{Discussion}

The terms cam- and pincer-type impingement have only recently been introduced, but abnormalities of hip morphology have long been identified as causes of OA of the 
hip. ${ }^{25-27}$ Harris reported that about $80 \%$ of cases of OA of the hip are related to abnormal hip morphology such as acetabular dysplasia. ${ }^{16,28}$ Other disorders such as SCFE $^{29}$ and Perthes' disease are also involved. ${ }^{30}$ Stulberg et $\mathrm{al}^{25}$ described the pistol-grip deformity, and reported it to be present in $40 \%$ of hips with OA. It was also the characteristic deformity of the femoral head and neck in patients with a history of slipped epiphysis. In a study on patients undergoing hip resurfacing arthroplasty, Beaulé et $\mathrm{al}^{31}$ found that over $50 \%$ of patients with end-stage OA had an insufficient head-neck offset consistent with cam-type FAI. Murray $^{26}$ suggested that OA could develop secondary to a deformity (posterior head tilt) because of a mild slipped epiphysis. Resnick ${ }^{32}$ also noted the posterior head tilt in osteoarthritic hips, but he suggested that it was an acquired deformity created by the formation of osteophytes and remodelling of the femoral head secondary to a degenerative process. However, Goodman et $\mathrm{al}^{33}$ found that the incidence of this deformity did not change with age and therefore was not secondary to degeneration.

Our study is the first of our knowledge to document the prevalence of bilateral deformities in symptomatic cam impingement in adult patients; most of the literature has focused on cadaver studies. ${ }^{33}$ Goodman et al $^{33}$ inspected the hips of 2665 skeletons for signs of post-slip morphology such as loss of normal concavity of the anterosuperior head-neck junction, increased concavity posteroinferiorly, a fovea located posterior to the axis of the femoral neck and posterior tilt of the edge of the articular surface of the femoral head. They noted post-slip deformity in 215 skeletons, a prevalence of $6 \%$, with $122(56.7 \%)$ of these having bilateral deformities. Others have reported the prevalence of bilateral SCFE using radiological studies with values ranging between $63 \%$ and $79 \% .^{29,34,35}$

The strong bilateral prevalence and the correlation between the side-to-side alpha angles may suggest a deformity which is congenital and not acquired as with SCFE. In addition, Beaule et $\mathrm{al}^{5}$ found that hips with FAI did not have an increased posterior concavity as would be expected with SCFE. ${ }^{36}$ Goodman et al $^{33}$ considered the possibility that the deformity which they were studying was an anatomical variant rather than acquired. Siebenrock et $\mathrm{al}^{37}$ reported an increase in the lateral epiphyseal extension in patients with cam-type impingement compared with a control group and suggested that it was a growth abnormality. More importantly, the degree of cam deformity which predisposes a patient to develop symptoms is still unclear. Our study suggests that patients with alpha angles of less than or equal to $60^{\circ}$ are less likely to develop hip pain. Longer follow-up over several decades will be required to assess the impact of the deformity and the development of degenerative changes since only $26 \%$ of patients in our series had bilateral symptoms despite $78 \%$ having bilateral deformities. These findings are somewhat analogous to those of hip dysplasia $^{16,38}$ and osteonecrosis, ${ }^{39}$ in both of which the severity of the deformity is known to affect the development of hip pathology. In their classic study on the natural history of hip dysplasia, Murphy et $\mathrm{al}^{16}$ found that a centreedge angle of less than $16^{\circ}$ was associated with the development of OA of the hip, obviously leaving a subgroup of patients with hip dysplasia (centre-edge angle of less than $25^{\circ}$ and greater than $16^{\circ}$ ) which did not have the pathological changes associated with the disease process. Although the presence of a cam deformity has been documented in patients with advanced arthritis of the hip, ${ }^{40}$ this association does not necessarily prove causation. ${ }^{41}$ More importantly, our study cannot predict the fate of those hips without pain, but with a cam deformity, because of the lack of long-term follow-up. However, we can say that the mere presence of an osseous abnormality may not fully explain the predisposition to the development of hip pain; other factors such as pelvic mobility may play a key role in the development of symptomatic cam impingement, as recently reported by Lamontagne, Kennedy and Beaule. ${ }^{42}$

In our study we also found that $42 \%$ of hips had an acetabular abnormality, of which $23.9 \%$ had retroversion and $17.9 \%$ had coxa profunda. Beck et $\mathrm{al}^{3}$ reported that of 57 hips with cam-type impingement, $27(47.4 \%)$ also had an abnormality of the acetabulum (17 coxa profunda, 2 coxa protrusio, 8 retroversion). Peters and Erickson ${ }^{8}$ reported that $48 \%$ of patients treated for cam impingement also had retroversion of the acetabulum. These findings have implications in defining which aspect of the deformity is most responsible for hip pain and potential cartilage damage. Of interest was the fact that our study showed that the severity of a cam deformity was a predictor of the development of hip pain, but that the significance of a pincer deformity was uncertain. However, our confidence interval was wide for this variable making a type II error possible. Further research is required to determine if the associated pincer deformity needs to be corrected in every case of symptomatic cam deformity. In addition, the fact that the larger cam deformities were at significantly greater risk of producing hip pain has important implications with respect to the aetiology of labral tears. Although recent studies ${ }^{43-45}$ have reported an association between labral tears and bony abnormalities, this again does not necessarily establish causation. When Bardakos, Vasconcelos and Villar ${ }^{46}$ compared the clinical outcome of patients with labral tears who had either isolated labral debridement or a combination of debridement and femoral osteoplasty, there was no significant difference in clinical outcome between the two groups, although there was a higher proportion of excellent results in the group which did undergo femoral osteoplasty. There were some limitations in that report as there was insufficient power to detect a significant difference, which was acknowledged by the authors. However, they did not examine the severity of the cam deformity and its possible relationship to the clinical outcome. Based on our findings this probably has a role.

A weakness of our study was the fact that it was retrospective. It would have been of interest to check how many asymptomatic hips with increased alpha angles had a 
positive impingement sign; but this was not reliably recorded on the contralateral hip. In addition, it would have been interesting to compare ranges of movement between the symptomatic and asymptomatic sides, but since patients with FAI can present with a wide range of movement despite having an elevated alpha angle, ${ }^{19}$ we are not sure that this would have added very much to our findings. More importantly, a recent study has shown that physical examination of patients with impingement has only fair observer reliability. ${ }^{47}$ In addition, radiographs of the hip are not necessarily taken perpendicular to the maximum prominence of the deformity and can lead to an underestimate of the alpha angle. MRI with radial reformatting would have been the best method for assessing the cam deformity and in demonstrating its maximum deformity. ${ }^{4}$ This underestimate of the true alpha angle on plain radiographs may have caused us to miss some cases of cam impingement altogether. This is well illustrated in Figure 3 in which the prominence lay superiorly, not perpendicular to the $\mathrm{x}$-ray beam, and the measured alpha angle on the lateral radiograph did not quantify the deformity accurately.

In conclusion, most patients with cam-type FAI have bilateral deformities even though most will be asymptomatic at the time of presentation. This may have long-term implications, and therefore screening of the contralateral hip may provide important information for both the patient and surgeon in determining the best timing for surgical intervention. Physicians should consider obtaining appropriate radiographs of the contralateral hip when diagnosing a patient with FAI. However, further longitudinal studies are required to determine which hips with a cam-type deformity will ultimately develop symptoms, or whether surgical treatment for FAI can prevent the development of OA.

No benefits in any form have been received or will be received from a commer cial party related directly or indirectly to the subject of this article.

\section{References}

1. Ganz R, Parvizi J, Leunig M, Siebenrock KA. Femoroacetabular impingement: a cause for osteoarthritis of the hip. Clin Orthop 2003;417:112-20.

2. Beaulé PE, Zaragoza EJ. Femoroacetabular impingement: diagnosis and treatment. In: Beaulé PE, ed. The young adult with hip pain. Rosemont, etc American Academy of Orthopaedic Surgeons, 2007:63-74.

3. Beck M, Kalhor M, Leunig M, Ganz R. Hip morphology influences the pattern of damage to the acetabular cartilage: femoroacetabular impingement as a cause of early osteoarthritis of the hip. J Bone Joint Surg [Br] 2005;87-B:1012-18.

4. Ito K, Minka MA 2nd, Leunig S, Werlen S, Ganz R. Femoroacetabular impingement and the cam-effect: a MRI-based quantitative anatomical study of the femoral head-neck offset. J Bone Joint Surg [Br] 2001;83-B:171-6.

5. Beaulé PE, Zaragoza EJ, Motamedic K, Copelan N, Dorey J. Three-dimensional computed tomography of the hip in the assessment of femoro-acetabular impingement. J Orthop Res 2005;23:1286-92.

6. Snow SW, Keret D, Scarangella S, Bowen JR. Anterior impingement of the femoral head: a late phenomenon of Legg-Calve-Perthes' disease. J Pediatr Orthop 1993;13:286-9.

7. Leunig M, Casillas MM, Hamlet M, et al. Slipped capital femoral epiphysis: early mechanical damage to the acetabular cartilage by impingement of the prominent femoral metaphysis. Acta Orthop Scand 2000;71:370-5.

8. Peters CL, Erickson JA. Treatment of femoro-acetabular impingement with surgical dislocation and debridement in young adults. J Bone Joint Surg [Am]2006;88-A:1735-41.
9. Beck M, Leunig M, Parvizi J, et al. Anterior femoroacetabular impingement. Part II: midterm results of surgical treatment. Clin Orthop 2004;418:67-73.

10. Murphy SB, Tannast M, Kim Y-J, Buly RL, Millis MB. Debridement of the adult hip for femoroacetabular impingement: indications and preliminary clinical results. Clin Orthop 2004;429:178-81.

11. Beaulé PE, LeDuff MJ, Zaragoza EJ. Quality of life following femoral head/neck osteochondroplasty for femoroacetabular impingement. J Bone Joint Surg [Am] 2007;89-A:773-9.

12. Siebenrock KA, Schoeniger R, Ganz R. Anterior femoro-acetabular impingement due to acetabular retroversion: treatment with periacetabular osteotomy. J Bone Joint Surg [Am] 2003;85-A:278-86.

13. Mankin HJ. Nontraumatic necrosis of bone (osteonecrosis). $N$ Engl J Med 1992;326:1473-9.

14. Trousdale RT, Ekkernkamp A, Ganz R, Wallrichs SL. Periacetabular and intertrochanteric osteotomy for the treatment of osteoarthrosis in dysplastic hips. $J$ Bone Joint Surg [Am] 1995;77-A:73-85.

15. Sharifi E, Sharifi H, Morshed S, Bozic KJ, Diab M. Cost-effectiveness analysis of periacetabular osteotomy. J Bone Joint Surg [Am] 2008;90-A:1447-56.

16. Murphy SB, Ganz R, Muller ME. The prognosis in untreated dysplasia of the hip: a study of radiographic factors that predict the outcome. J Bone Joint Surg [Am] 1995;77-A:985-9.

17. Tönnis D. Normal values of the hip of the hip joint for the evaluation of $x$-rays in children and adults. Clin Orthop 1976;119:39-47.

18. Wiberg G. Studies on dysplastic acetabula and congenital subluxation of the hip joint: with special reference to the complication of osteoarthritis. Acta Chir Scand 1939;83:Suppl 58

19. Notzli HP, Wyss TF, Stoecklin CH, et al. The contour of the femoral head-neck junction as a predictor for the risk of anterior impingement. J Bone Joint Surg $[\mathrm{Br}]$ 2002;84-B:556-60.

20. Meyer DC, Beck M, Ellis T, Ganz R, Leunig M. Comparison of six radiographic projections to assess femoral head/asphericity. Clin Orthop 2006;445:181-5.

21. Reynolds D, Lucas J, Klaue K. Retroversion of the acetabulum: a cause of hip pain. J Bone Joint Surg [Br] 1999;81-B:281-8.

22. Jamali AA, Maldenov K, Meyer DC, et al. Anteroposterior pelvic radiographs to assess acetabular retroversion: high validity of the "cross-over-sign". J Orthop Res 2007:25:758-65

23. Kalberer F, Sierra RJ, Madan SS, Ganz R, Leunig M. Ischial spine projection into the pelvis: a new sign for acetabular retroversion. Clin Orthop 2008;466:677-83.

24. Siebenrock KA, Kalbermatten DF, Ganz R. Effect of pelvic tilt on acetabular retroversion: a study of pelves from cadavers. Clin Orthop 2003;407:241-8.

25. Stulberg SD, Cordell LD, Harris WH, Ramsey PL, MacEwen GD. Unrecognized childhood hip disease: a major cause of idiopathic osteoarthritis of the hip. In: Amstutz HC, ed. The hip. Procs Third Open Scientific Meeting C. V. Mosby, 1975:212-28.

26. Murray Ro. The aetiology of primary osteoarthritis of the hip. $\mathrm{Br} J$ Radiol 1965;38:810-24.

27. Ganz R, Leunig M, Leunig-Ganz K, Harris WH. The etiology of osteoarthritis of the hip: an integrated mechanical concept. Clin Orthop 2008;466:264-72.

28. Harris WH. Etiology of osteoarthritis of the hip. Clin Orthop 1986;213:20-33.

29. Dobbs MB, Weinstein SL. Natural history and long-term outcomes of slipped capital femoral epiphysis. Intr Course Lect 2001;50:571-5.

30. McAndrew MP, Weinstein SL. A long-term follow-up of Legg-Calvé-Perthes disease. J Bone Joint Surg [Am] 1984;66-A:860-9.

31. Beaulé PE, Harvey N, Zaragoza EJ, LeDuff M, Dorey FJ. The femoral head/neck offset and hip resurfacing. J Bone Joint Surg [Br] 2007;89-B:9-15.

32. Resnick $\mathbf{D}$. The tilt deformity of the femoral head in osteoarthritis of the hip: a poor indicator of previous epiphysiolysis. Clin Radiol 2003;27:355-63.

33. Goodman DA, Feighan JE, Smith AD, et al. Subclinical slipped capital femoral epiphysis: relationship to osteoarthritis of the hip. J Bone Joint Surg [Am] 1997;79A:1489-97.

34. Hansson G, Jerre R, Sanders SM, Wallin J. Radiographic assessment of coxarthrosis following slipped capital femoral epiphysis: a 32-year follow-up study of 151 hips. Acta Radiol 1993;34:117-23.

35. Billing L, Severin E. Slipping epiphysis of the hip: a roentgenographical and clinical based study based on a new roentgen technique. Acta Radiol Supp/ 1959;74:1-76.

36. Cohen MS, Gelberman RH, Griffin PP, et al. Slipped capital femoral epiphysis: assessment of epiphyseal displacement and angulation. J Pediatr Orthop 1986;6:259-64.

37. Siebenrock KA, Wahab KHA, Werlen S, et al. Abnormal extension of the femoral head epiphysis as a cause of cam impingement. Clin Orthop 2004;418:54-60.

38. Cooperman DR, Wallensten R, Stulberg D. Acetabular dysplasia in the adult. Clin Orthop 1980;175:79-85 
39. Mont MA, Hungerford DS. Non-traumatic avascular necrosis of the femoral head. J Bone Joint Surg [Am] 1995;77-A:459-74.

40. Tanzer M, Noiseux N. Osseous abnormalities and early osteoarthritis: the role of hip impingement. Clin Orthop 2004;429:170-7.

41. Hill AB. The environment and disease: association or causation? Proc $R$ Soc Med 1965;58:295-300.

42. Lamontagne M, Kennedy MJ, Beaule PE. The effect of cam FAl on hip and pelvic motion during maximum squat. Clin Orthop 2009;467:645-50.

43. Guevara CJ, Pietrobon R, Carothers JT, OIson SA, Vail TP. Comprehensive morphologic evaluation of the hip in patients with symptomatic labral tear. Clin Orthop 2006; $453: 277-85$
44. Wenger DE, Kendall KR, Miner M, Trousdale RT. Acetabular labral tears rarely occur in the absence of bony abnormalities. Clin Orthop 2004;426:145-50.

45. Peelle MW, Della Rocca GJ, Maloney WJ, Curry MC, Clohisy JC. Acetabular and femoral radiographic abnormalities associated with labral tears. Clin Orthop 2005;441:327-33.

46. Bardakos NV, Vasconcelos JC, Villar RN. Early outcome of hip arthroscopy for femoroacetabular impingement: the role of femoral osteoplasty in symptomatic improvement. J Bone Joint Surg [Br] 2008;90-B:1570-5.

47. Martin RL, Sekiya JK. The interrater reliability of 4 clinical tests used to assess individuals with musculoskeletal hip pain. J Orthop Sports Phys Ther 2008;38:71-7. 